4. Parachuri VR, Adhyapak SM, Kumar P, Setty R, Rathod R, Shetty DP. Ventricular restoration by linear endoventricular patchplasty and linear repair. Asian Cardiovasc Thorac Ann. 2008;16:401-6.
5. de Chillou C, Lacroix D, Klug D, Magnin-Poull I, Marquié C, Messier M, et al. Isthmus characteristics of reentrant ventricular tachycardia after myocardial infarction. Circulation. 2002;105:726-31.

\title{
Cardiopulmonary bypass strategy with low-dose heparin and nafamostat mesilate in cardiac surgery: A safe option for patients with acute stroke
}

\author{
Naoto Morimoto, MD, PhD, Soichiro Henmi, MD, Masato Yoshida, MD, and Nobuhiko Mukohara, MD, \\ Himeji, Japan
}

Patients undergoing open cardiac surgical procedures with a history of acute stroke pose a difficult management problem. There is always the risk that cardiopulmonary bypass (CPB) and heparinization may induce intracranial hemorrhage. A multicenter study suggests that open cardiac surgical procedures can be performed safely 4 weeks after stroke $^{1}$; however, some patients with acute cardiogenic stroke occasionally require emergency surgery because of uncontrollable heart failure or ongoing thromboembolism.

Heparinized CPB with low systemic heparinization is among the therapeutic options when operating on patients with the risk of intracranial hemorrhage; however, low systemic heparinization could allow clot formation. ${ }^{2}$ Nafamostat mesilate (6-amino-2-naphthyl $p$-guanidinobenzoate dimethanesulfonate, currently available in Japan and Korea) is a serine protease inhibitor that has such activities as anticoagulant effect (by inhibiting coagulation factors, XIIa, Xa, and VIIa, along with thrombin), antifibrinolytic activities (by inhibiting tissue-type and urokinase plasminogen activators), and antiplatelet actions. ${ }^{3,4}$ Because of a short halflife of 8 minutes, it has recently been used mainly as an anticoagulant for hemodialysis ${ }^{5}$ and extracorporeal membrane oxygenation ${ }^{6}$ in patients with bleeding tendencies. Nafamostat mesilate has been widely used in Japan as an alternative anticoagulant agent during hemodialysis, and its in vivo effect as an anticoagulant has been established. ${ }^{3}$

In this study, we report a successful CPB strategy with low-dose heparin and nafamostat mesilate as an

\footnotetext{
From the Narayana Hrudayalaya Institute of Medical Sciences, ${ }^{\text {a }}$ Bangalore, India; and the Department of Cardiology, ${ }^{\mathrm{b}}$ St. John's Medical College Hospital, Bangalore, India. Disclosures: Authors have nothing to disclose with regard to commercial support.

Received for publication Dec 13, 2011; revisions received March 2, 2012; accepted for publication March 16, 2012; available ahead of print April 27, 2012.

Address for reprints: Naoto Morimoto, MD, PhD, Department of Cardiovascular Surgery, Himeji Cardiovascular Center, 520, Saishoko, Himeji, Hyogo, 670-0981, Japan (E-mail: naotofrcs@gmail.com).

J Thorac Cardiovasc Surg 2012;144:726-8

0022-5223/ $\$ 36.00$

Copyright (c) 2012 by The American Association for Thoracic Surgery http://dx.doi.org/10.1016/j.jtcvs.2012.03.030
}

anticoagulant to reduce the dosage of heparin for patients with acute stroke.

\section{MATERIALS AND METHODS}

With approval of the institutional review board and patient informed consent, patients who underwent cardiac surgery with CPB with low-dose heparin and nafamostat mesilate were included. From November 2007 and January 2010, we had 17 patients with courses complicated by acute stroke. The patient characteristics are listed in Table 1. Acute stroke was detected by diffusion-weighted magnetic resonance images in 16 cases, and 1 patient had subarachnoid hemorrhage from a ruptured mycotic aneurysm. Of these patients, 14 patients had a diagnosis of active infective endocarditis according to modified Duke criteria. The remaining 3 patients had acute pulmonary embolism with atrial septal defect, left ventricular thrombus, or left atrial myxoma. Mean age was $63.9 \pm 16.7$ years. Seven patients $(41.2 \%)$ were female. The indication for the operation was uncontrolled sepsis in 7 patients, uncontrollable heart failure in 5 patients, and ongoing thromboembolism in 5 patients. The mean interval from the onset of stroke to surgery was $2.9 \pm 0.4$ days. All operations were performed as routine procedures except for the CPB anticoagulation management. Brain computed tomography was performed within 3 days after the surgery in all cases.

\section{Anticoagulation Protocol During CPB}

Anticoagulation during CPB was managed as follows: before connection of the extracorporeal circuit, $0.8 \mathrm{mg} / \mathrm{kg}$ of nafamostat mesilate and $50 \mathrm{IU} / \mathrm{kg}$ of heparin (our normal dosage for CPB is $300 \mathrm{IU} / \mathrm{kg}$ ) were administered to obtain a diatomaceous earth (Celite; World Minerals Inc, Santa Barbara, Calif) activated clotting time (DEACT, measured with ACTII; Medtronic Blood Management, Parker, Colo) over 250 seconds. If DEACT did not rise above 250 seconds, a 200-IU dose of heparin was administered. CPB was composed of a roller pump (Mera HAS; Senko Medical Instrument Mfg Co Ltd, Tokyo, Japan), a silicon- and heparin-coated hollow-fiber polypropylene oxygenator (Mera NHP Excelung Prime HPO23WH-C; Senko) and a heparin-coated bypass circuit (Mera Exceline-S, 0.5-inch; Senko). After connection to the pump circuit, nafamostat mesilate and heparin were continuously infused through the venous line of the pump circuit at $0.8 / \mathrm{mg} /(\mathrm{kg} \cdot \mathrm{h})$ and $25 \mathrm{IU} /(\mathrm{kg} \cdot \mathrm{h})$, respectively. DEACT, for which blood samples were taken from the venous circuit line every 10 minutes, was maintained between 400 and 600 seconds during CPB. If DEACT exceeded 600 seconds, the continuous infusion of heparin was reduced. An additional bolus injection of $100 \mathrm{IU}$ of heparin was administrated when DEACT fell below 400 seconds. Furthermore, kaolin-measured ACT (KACT, measured with Hemochron401; International Technidyne Corp, Edison, $\mathrm{NJ})$ was monitored simultaneously. KACT reflects the heparin activity in 
TABLE 1. Summary of data

\begin{tabular}{|c|c|c|c|c|c|c|c|c|}
\hline $\begin{array}{c}\text { Case } \\
\text { no. } \\
\end{array}$ & $\begin{array}{c}\text { Age } \\
(\mathbf{y})\end{array}$ & Sex & Diagnosis & Neurologic history & Operation and time to surgery & $\begin{array}{c}\text { ECC time } \\
(\mathrm{min})\end{array}$ & $\begin{array}{c}\text { Blood loss } \\
(\mathrm{g})\end{array}$ & Outcome \\
\hline 1 & 54 & M & NVE (mitral) & Right parietal hemorrhagic infarct & $\operatorname{MVR}(0 \mathrm{~d})$ & 138 & 540 & Alive \\
\hline 2 & 63 & M & NVE (mitral) & Multiple infarcts & $\operatorname{MVR}(4 \mathrm{~d})$ & 210 & 280 & Alive \\
\hline 3 & 75 & M & NVE (aortic) & Multiple infarcts & $\operatorname{AVR}(0 \mathrm{~d})$ & 106 & 580 & Alive \\
\hline 4 & 62 & $\mathrm{~F}$ & NVE (mitral) & Multiple infarcts & $\operatorname{MVR}(14 \mathrm{~d})$ & 106 & 170 & Alive \\
\hline 5 & 84 & $\mathrm{~F}$ & NVE (aortic), AP & SAH & AVR, CABG (28 d) & 241 & 830 & Alive \\
\hline 6 & 78 & M & NVE (aortic/mitral) & Right parietal infarct & AVR, MVR (17 d) & 257 & 330 & Alive \\
\hline 7 & 38 & M & NVE (aortic/mitral) & Multiple infarcts & $\operatorname{MVR}(11 \mathrm{~d})$ & 176 & 360 & Alive \\
\hline 8 & 64 & $\mathrm{~F}$ & NVE (mitral) & Multiple infarcts & MVR, CABG (1 d) & 155 & 560 & Alive \\
\hline 9 & 69 & M & NVE (aortic/mitral) & Right frontal infarct & AVR, MVR (1 d) & 313 & 670 & Alive \\
\hline 10 & 81 & $\mathrm{~F}$ & NVE (mitral) & Left occipital infarct & $\operatorname{MVR}(3 \mathrm{~d})$ & 157 & 200 & Alive \\
\hline 11 & 70 & M & NVE (mitral) & Multiple infarcts & $\operatorname{MVR}(3 \mathrm{~d})$ & 198 & 340 & Alive \\
\hline 12 & 67 & M & NVE (aortic) & Multiple infarcts & $\operatorname{AVR}(3 d)$ & 103 & 600 & Alive \\
\hline 13 & 22 & M & NVE (mitral) & Multiple infarcts & $\operatorname{MVR}(1 \mathrm{~d})$ & 181 & 290 & Alive \\
\hline 14 & 79 & $\mathrm{~F}$ & PVE (aortic) & Multiple infarcts & $\operatorname{AVR}(3 \mathrm{~d})$ & 151 & 450 & Alive \\
\hline 15 & 79 & $\mathrm{~F}$ & Acute PTE, ASD & Right frontal infarct & ASD closure, $\mathrm{PE}(3 \mathrm{~d})$ & 115 & 1780 & Alive \\
\hline 16 & 45 & M & LV thrombus, AMI & Left frontal infarct & CABG, removal of thrombus ( $2 \mathrm{~d}$ ) & 58 & 210 & Alive \\
\hline 17 & 57 & $\mathrm{~F}$ & LA myxoma & Right lower occipital infarct & Resection of LA myxoma (3 d) & 57 & 100 & Alive \\
\hline
\end{tabular}

ECC, Extracorporeal circulation; $M$, male; $N V E$, native valve endocarditis; $M V R$, mitral valve replacement; $A V R$, aortic valve replacement; $F$, female; $A P$, angina pectoris; $S A H$, subarachnoid hemorrhage; $C A B G$, coronary artery bypass grafting; $P V E$, prosthetic valve endocarditis; $P T E$, pulmonary thromboembolism; $A S D$, atrial septal defect; $P E$, pulmonary embolectomy; $L V$, left ventricular; $A M I$, acute myocardial infarction; $L A$, left atrial.

the blood under the combined use of nafamostat mesilate because kaolin absorbs nafamostat mesilate, thus minimizing its effect on KACT. ${ }^{7}$ The value of KACT was kept between 200 and 300 seconds. If the KACT reading fell below 200 seconds, a 200-IU dose of heparin was added.

The pump flow was set at 2.4 to $2.6 \mathrm{~L} /\left(\mathrm{min} \cdot \mathrm{m}^{2}\right)$. All patients were cooled to mild hypothermia $\left(33^{\circ} \mathrm{C}-34^{\circ} \mathrm{C}\right)$. Target mean systemic blood pressure was $60 \mathrm{~mm} \mathrm{Hg}$. Cerebral oxygenation was monitored with a nearinfrared oxygen monitor (INVOS 4100; Somanetics Corporation, Troy, Mich). The pump flow was adjusted to keep the cerebral oxygenation saturation value the same as at the anesthetic induction. After weaning from $\mathrm{CPB}$ and decannulation, residual heparin was reversed with protamine sulfate. Dosage of protamine sulfate was $1 \mathrm{mg}$ for every $100 \mathrm{IU}$ of initial heparin.

\section{RESULTS}

Mean dosages of nafamostat mesilate and heparin were $164 \pm 64 \mathrm{mg}$ and $704 \pm 314 \mathrm{IU}$, respectively. The changes in DEACT and KACT during CPB are shown in Figure 1. Total blood loss and homologous red blood cell and blood requirements were $487 \pm 387 \mathrm{~g}, 437 \pm 359 \mathrm{~mL}$, and 673 $\pm 456 \mathrm{~mL}$, respectively. In-hospital mortality was $0 \%$. Postoperative brain computed tomography demonstrated neither deterioration nor a new occurrence of intracranial hemorrhage in all patients.

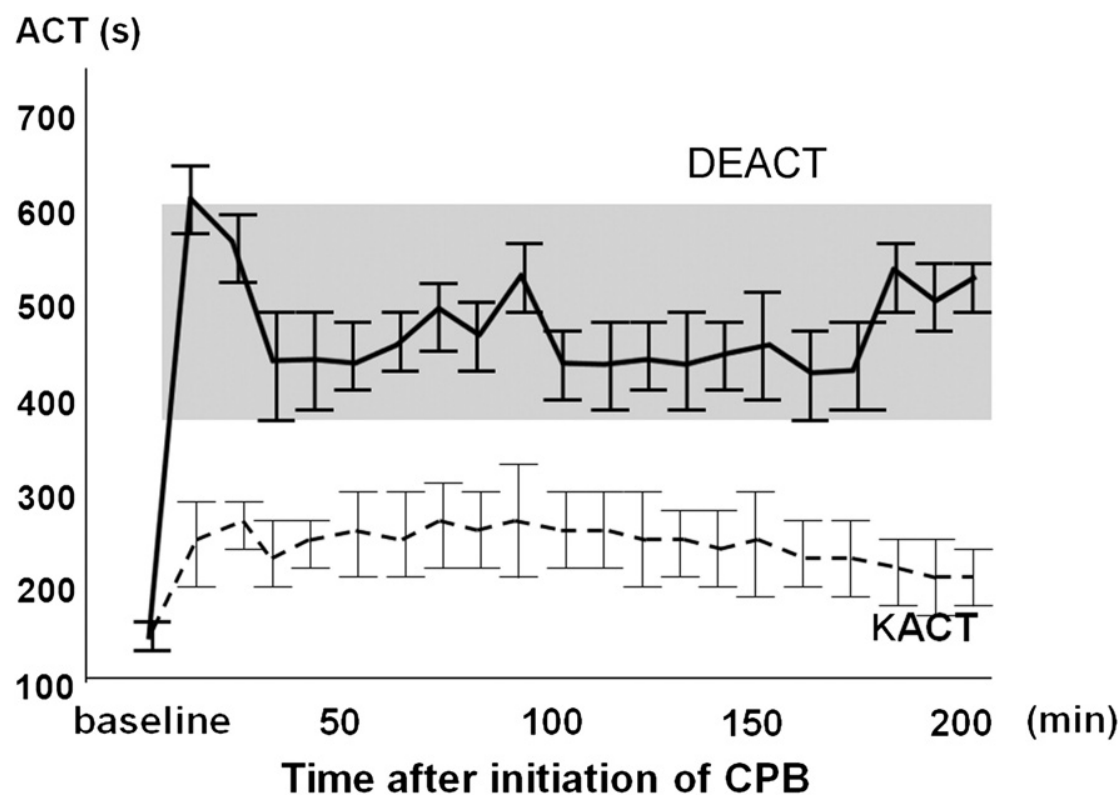

FIGURE 1. Diatomaceous earth- and kaolin-derived clotting time $(A C T)$ values during cardiopulmonary bypass $(C P B)$. Gray zone represents target range for diatomaceous earth-derived activated clotting time. 


\section{DISCUSSION}

Nafamostat mesilate has been used as an anticoagulant in substitution for heparin in the situations of $\mathrm{CPB}$, left ventricular assist devices, and hemodialysis. The main advantages of nafamostat mesilate are its short half-life and its functioning to inactivate coagulation, fibrinolysis, and platelet aggregation. Murase and colleagues ${ }^{8}$ demonstrated that nafamostat mesilate inhibits fibrinolysis, preserves platelet function during $\mathrm{CPB}$, and reduces blood loss. Ota and associates ${ }^{9}$ demonstrated successful CPB management with mesilate for 3 patients with recent intracranial hemorrhage. Both groups emphasized that inhibition of fibrinolysis activation was the most important supplementary effect of nafamostat mesilate, because as excessive fibrinolysis can cause intracranial bleeding during and after $\mathrm{CPB} .{ }^{8,9}$ On the other hand, heparin enhances fibrinolytic activity during $\mathrm{CPB}$, leading to dissolution of clots and recurrence of bleeding. In this study we demonstrated successful CPB management with a continuous infusion of nafamostat mesilate in open heart surgical procedures for patients after acute stroke.

Some authors have maintained that low-dose heparin can achieve adequate anticoagulation during $\mathrm{CPB}$, but Ovrum and coworkers ${ }^{2}$ reported that clot formation in the cardiotomy reservoir occurred during $\mathrm{CPB}$ with lowdose heparin. In our opinion, low-dose heparinization during CPB should not be routinely used because of the risk of clot formation; however, it provides an advantage for patients with the risk of bleeding. We believe that the combination of low-dose heparin and nafamostat mesilate can produce safer anticoagulation than can lowdose heparin.

Limitations to the current study include small sample size, the lack of a control group, the lack of data on fibrinolysis, and the study's retrospective nature. Further prospective analysis is needed to confirm the advantage of our CPB strategy with low-dose heparin and nafamostat mesilate for patients with bleeding risks.

\section{References}

1. Eishi K, Kawazoe K, Kuriyama Y, Kitoh Y, Kawashima Y, Omae T. Surgical management of infective endocarditis associated with cerebral complications: Multicenter retrospective study in Japan. J Thorac Cardiovasc Surg. 1995;110:1745-55.

2. Ovrum E, Tangen G, Tollofsrud S, Oystese R, Ringdal MA, Istad R. Comparison of two heparin-coated extracorporeal circuit with reduced systemic anticoagulation in routine coronary artery bypass surgery. J Thorac Cardiovasc Surg. 2001;121:324-30.

3. Aoyama T, Ino Y, Ozeki M, et al. Pharmacological studies of FUT-175, nafamostat mesilate. I. Inhibition of protease activity in in vitro and in vivo experiments. Jpn J Pharmacol. 1984;35:203-27.

4. Okajima K, Uchiba M, Murakami K. Nafamostat mesilate. Cardiovasc Drug Rev. 1995; 13:51-65

5. Yang JW, Han BG, Kim BR, Lee YH, Kim YS, Yu JM, Choi SO. Superior outcome of nafamostat mesilate as an anticoagulant in patients undergoing maintenance hemodialysis with intracerebral hemorrhage. Ren Fail. 2009;31:668-75.

6. Kotani K, Ichiba S, Andou M, Sano Y, Date H, Tedoriya T, et al. Extracorporeal membrane oxygenation with nafamostat mesilate as an anticoagulant for massive pulmonary hemorrhage after living-donor lobar lung transplantation. J Thorac Cardiovasc Surg. 2002;124:626-7.

7. Despotis GJ, Gravlee G, Filos K, Levy J. Anticoagulation monitoring during cardiac surgery: a review of current and emerging techniques. Anesthesiology. 1999; 91:1122-51.

8. Murase M, Ushi A, Tomita Y, Maeda M, Koyama T, Abe T. Nafamostat mesilate reduces blood loss during open heart surgery. Circulation. 1993;88(5 Pt 2):II432-6.

9. Ota T, Okada K, Kano H, Okita Y. Cardiopulmonary bypass using nafamostat mesilate for patients with infective endocarditis and recent intracranial hemorrhage. Interact Cardiovasc Thorac Surg. 2007;6:270-3.

\title{
Transcatheter aortic valve implantation combined with conventional heart surgery: Hybrid approach for complex cardiac pathologic features
}

\author{
Miralem Pasic, MD, PhD, Semih Buz, MD, Axel Unbehaun, MD, and Roland Hetzer, MD, PhD, Berlin, \\ Germany
}

A new hybrid approach, the combination of transcatheter aortic valve implantation (TAVI) and conventional cardiac

\footnotetext{
From the Department of Cardiovascular Surgery, Himeji Cardiovascular Center, Himeji, Japan.

Disclosures: Drs Pasic, Unbehaun, and Buz have been proctors to Edwards Lifesciences since July 2009. All other authors have nothing to disclose with regard to commercial support.

Received for publication Feb 1, 2012; revisions received March 13, 2012; accepted for publication March 19, 2012; available ahead of print April 16, 2012.

Address for reprints: Miralem Pasic, MD, PhD, Deutsches Herzzentrum Berlin, Augustenburger Platz 1, Berlin 13353, Germany (E-mail: pasic@dhzb.de).

J Thorac Cardiovasc Surg 2012;144:728-31

$0022-5223 / \$ 36.00$

Copyright ( $) 2012$ by The American Association for Thoracic Surgery

http://dx.doi.org/10.1016/j.jtcvs.2012.03.056
}

surgery, might be a possible solution for patients considered not suitable for complex conventional surgery. We have summarized our preliminary experience. ${ }^{1-3}$

\section{BRIEF CLINICAL REPORT}

From April 2008 to October 2011, 11 patients underwent simultaneous conventional cardiac surgery and TAVI with or without additional percutaneous coronary intervention (PCI) (Table 1). Ten patients had severe aortic valve stenosis, and one (patient 11) had pure insufficiency. The combined procedure was the first heart operation in 6 patients, the second in 3 patients, the third in 1 patient, and the fourth in 1 patient. 